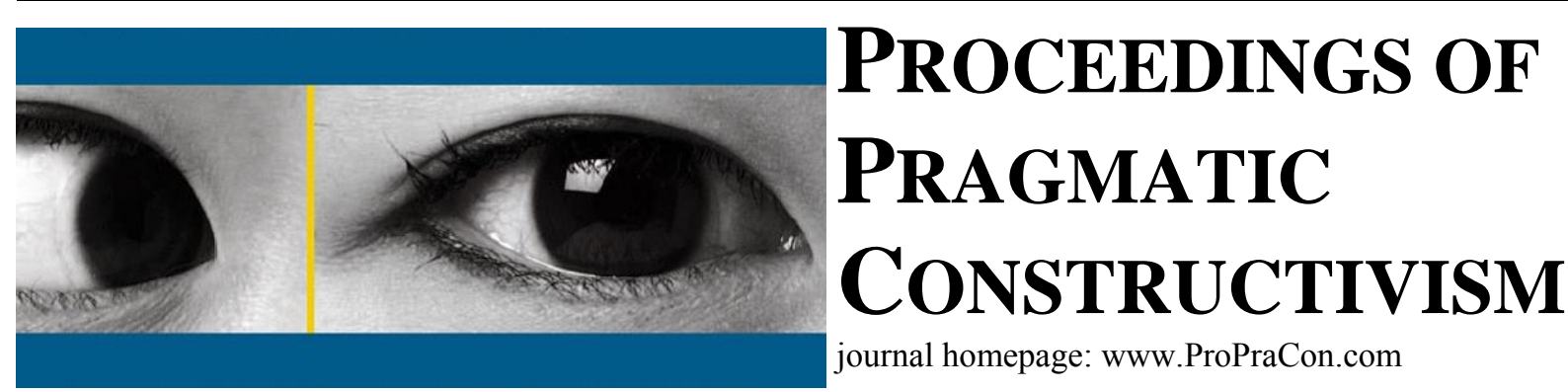

\title{
The illusion of New Public Management? An analysis of performance-based budgeting in the public sector
}

\author{
Lino Cinquini \\ Professor of Business Administration and Management Accounting \\ Scuola Superiore Sant'Anna; Institute of Management \\ Piazza Martiri della Libertà, 24; 56127 Pisa; Italy; l.cinquini@sssup.it \\ Sara Giovanna Mauro \\ $\mathrm{PhD}$ in Management \\ Scuola Superiore Sant'Anna; Institute of Management \\ Piazza Martiri della Libertà, 24; 56127 Pisa; Italy; s.mauro@sssup.it \\ Daniela Pianezzi \\ $P h D$ in Management \\ Scuola Superiore Sant'Anna; Institute of Management \\ Piazza Martiri della Libertà, 24; 56127 Pisa; Italy; d.pianezzi@sssup.it
}

Keywords: New Public Management; Performance Based Budgeting; reality vs illusion in pragmatic constructivism.

\section{Research topic and background}

The present research wishes to adopt a pragmatic constructivist approach in order to understand and explain the functionality of private- inspired reforms in the public sector. In particular, the research investigates the introduction and implementation of a relevant but challenging managerial reform, performance- based budgeting (PBB), become widespread in the public sector worldwide.

PBB is one of the labels whereby mechanisms and procedures designed to use performance information during the budgeting process have become widespread (OECD, 2007; Robinson, 2007). Despite its faraway origins, PBB has gained renewed attention as a component of the broadest reform movement known under the umbrella term of New Public Management (NPM) (Hood, 1991, 1995; Hyndman et al., 2014). Indeed, the focus on measuring and managing performance that drives PBB is at the heart of the NPM movement. The main rationale beyond this reform movement lies in the assumption about the public goodness of the management of private corporations (Stiglitz, 1989) to improve efficiency and effectiveness of the public sector. Therefore, since the 1980s, the public sector has undertaken waves of reforms inspired by the private sector in order to improve its performance.

The feasibility and usefulness of this approach has been object of great scrutiny and debate. Indeed, on the one hand, NPM has been criticized because of its poor implementation and difficulties in meeting the initial expectations (Lapsley, 2008; Lynn, 1998). Scholars have critically underlined how a managerial approach in the public sector can lead to the diffusion of an entrepreneurial ethos (Morales et al., 2014), transforming the public servant in a new homo oeconomicus (Hoskin, 2015) with the risk of privatizing moral concerns (Dobel, 1978), penalizing the public sphere (Lehman, 2010) and the common understanding of public interest (Johnston, 2015). On the other hand, previous studies have pointed out that although the inevitable paradoxes linked to a new reform movement as NPM, it can still worth the efforts (Dan and Pollitt, 2014; Hood and Peters, 2004), and indeed it still plays an influencing role in the current public sector agenda (de Vries and Nemec, 2013). However, the general principles of NPM call for adaptation in light of the specific context where they have to be applied. As ter Bogt et al. (2015) pointed out through their empirical analysis on PBB, the practice challenges NPM assumptions and call for adaptation to be realizable. 


\section{Theoretical approach and research questions}

In light of these considerations, the present research studies PBB as an example of controversial and challenging reform introduced in the public sector in the spirit of NPM. Taking into account its high hopes but often disappointing achievements, as Dean claimed already at the end of the 1980s, the present research wishes to improve the understanding of PBB by investigating under a pragmatic constructivist perspective whether, why and under which conditions this new model is able to construct 'reality' or produces instead an 'illusion' (Norreklit 2011).

According to the pragmatic constructivist paradigm (Nørreklit et al. 2006), PBB constitutes the base for action and it works properly only to the extent that its theoretical assumptions and foundations (i.e. the narrative of the reform) are translated into practice. PBB is a social construct that aims at generating a set of general conditions for successful actions. In the terminology of pragmatic constructivism, social constructs as such are called "topos" and consist of an integration of four dimensions: facts, logic/possibilities, values and communication. A topos comprises "concepts used and common interpretations of the relevant concerns and arguments" (Nørreklit et al., 2006). It entails visions of the world and leads to the elaboration of alternative possibilities of action. In other words, a topos embeds values, defines alternative possibilities - factual and nonfactual- and requires the communication between actors in order to be shared and enacted. In this view, a topos can be valid in that it expresses a successful representation of the world or it can instead produce illusions that incapacitate the actors and generate disastrous consequences. Illusions are "non-functional relations between actor and world"(Nørreklit, 2011, 19), while reality consists of a "functioning actor-world relationship" (Nørreklit, 2011, 19, see Fig. 1). In accordance with this view, PBB is a valid tool if it properly integrates the four aspects of reality, where "validity" means adequacy to reality.

Fig. 1 Reality as relation (Norreklit, 2011)

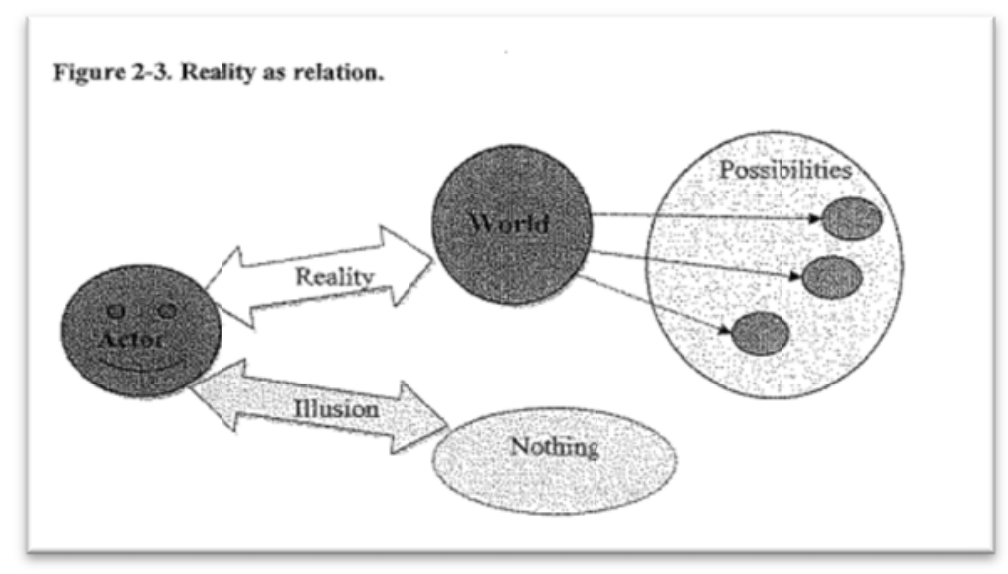

In order to understand if PBB results in illusionary constructs, we need to investigate the practice of PBB insofar as "the criteria for distinguishing between reality and illusion are pragmatic" (Nørreklit, 2011, 19). In other words, PBB is valid (i.e. produces reality rather than illusion) if the reform/topos realises the intended goals.

A functioning integration of values, communication, possibilities and facts is necessary, but not sufficient to establish reality. The integration of facts, possibilities and values become a reality when they are communicated, otherwise only individual disconnected realities exist. In this theoretical framework, communication is a necessary condition for inter-subjective reality; communication is the conditio sine qua non for cooperation inside an organization and between organizations. As Mitchell et al. (2013) have explained, "each actor has his own perspectives on facts, possibilities and values [...] they have to be coordinated and combined with the facts, possibilities and values of the other actors though the communication [...] overarching company topoi are needed to facilitate a network of mutual understanding that enables this cooperation." Furthermore, only if there is a convergence of different topoi, by means of communication, it is possible to achieve common organizational visions and organizational goals (Cinquini et al., 2013). In the light of this perspective, the translation of PBB into practice depends also on the way in which the reform has been communicated and understood by the public administrators. In addition, the reform should be able to adapt to the context it aims to change, otherwise it foresees possibilities that are not factual and it promotes values conflicting with the behaviours and ethics of the public administrators. As result of this non-functional topos, illusions may orient actors' decision-making and daily practices. 
In order to assess the validity of $\mathrm{PBB}$, the work investigates, analyses, and compares legislative requirements and guidelines (model) with the documents adopted and published in implementing the reform (practice) and the opinions expressed by actors (narrative). Therefore, the research aims at pointing out whether PBB practice is consistent with the model and whether, in its turn, PBB narrative is consistent with PBB model and practice. If model, practice and narrative are consistent each other, PBB is able to create a reality, otherwise it produces illusions and failures (Norreklit, 2011).

\section{Research setting and method}

The empirical evidence to support the research is collected at the central level of government in Italy. This country provides new evidence due to its recent attempts to introduce PBB compared to the Anglo-Saxon world. Therefore, the country is now facing many of the challenges implied by the reform thus representing a suitable ground for achieving the final goal of the research. A qualitative approach is adopted to achieve an in-depth understanding of the practice in its context through the realization of a single case study (Yin, 1994). The reliability of the research findings is achieved through the triangulation of different sources of data. Each source allows operationalizing a component of the theoretical approach. In particular, since the current study aims at analysing whether PBB is able to construct a reality or not through the analysis of the consistency between model, practice and narrative, data are gathered in order to understand each of these levels of analysis. Firstly, the model is studied through the analysis of legislative texts, reports and guidelines produced by national authorities (e.g., ANAC). These documents would set rules and principles of PBB thus defining its overarching framework. Secondly, the practice is interpreted through the study of the documents adopted by the organizations in implementing PBB, as the budget documents, performance plans and performance reports. Finally, the narrative is pointed out through semi-structured and face-to-face interviews done with experts at the central level of government. In particular, the unit of analysis is represented by a ministry and the experts are selected from different units in order to collect opinions from the main groups involved in PBB. Namely, these units are the independent performance unit (OIV), the division 'Economic and financial management and planning' of the Responsibility Center of the ministry, and the unit responsible for the ministry's budget in the Ministry of Finance.

\section{Preliminary findings}

The preliminary analysis of these data underlines two main kinds of inconsistencies between PBB model, practice and narrative: conceptual and implementation inconsistencies. The latter result from a failure of the reform in terms of communication of aims and drivers, definition of factual possibilities, and promotion of values. The first kind refers to terminology confusion ("what" dimension) and to PBB potentially contrasting goals ("why" dimension). The empirical analysis has demonstrated how challenging is to define univocally the concept of performance in the public sector, operationalize and measure it accordingly. The difficulty in defining performance is influenced and influences the difficulty in agreeing on the goal(s) to reach: does PBB represent a control tool for the public managers or is it designed to address citizens' needs thus improving external accountability? Consequently, these inconsistencies result in the second kind of inconsistencies identified about the implementation of PBB ("how" dimension). This latter analysis points out the main issues that challenges the realization of PBB at the central level of government. Furthermore, PBB implies a set of values borrowed from the private sector (e.g. efficacy and efficiency) which often conflict with the ethics of public servants and with their idea about the objectives and mission that public organizations should pursue.

\section{Expected contributions and implications from the development of research}

The empirical analysis underlines the limits of NPM by pointing out the inconsistencies of PBB, which challenge and impede the functionality of this private-inspired reform in the public sector. The faith in the effectiveness of the translation of private sector performance practices into the public sector underestimates the problem of measuring outcomes of "public policies" and the need of a cultural and organizational change in the public sector that could not take place through top-down processes. Further, the myth of the clear separation between politics and administration in terms of decision-making processes and implementing procedures does not fit with public sector reality. Therefore, the research stresses the need of understanding the conditions under which the functionality of PBB could be realized. This purpose is fulfilled by extending the use of the conceptual dichotomy between reality and illusion. By adopting this approach, the research aims at contributing to the literature on performance budgeting by deepening the understanding of its functionality through a focus on the integration between three levels of analysis (model, practice and narrative). Further, the study seeks to contribute to the debate on NPM by providing empirical evidence on the conditions which affects the functionality of private-inspired reforms in and for the public sector. Finally, the research wishes to enrich 
Proceedings of Pragmatic Constructivism (2016) Vol. 6, No. 1, 14-25

and extend the literature on pragmatic constructivism by using its key concepts to develop an understanding of what are the conditions for successful practices in a specific context and as they result from the coherence between model, practice and narrative. 


\section{THE ILLUSION OF NEW PUBLIC MANAGEMENT? An analysis of performance-based budgeting in the public sector}

Lino Cinquini, Sara Giovanna Mauro and Daniela Pianezzi

Sixth Conference on Actor-Reality Construction 01 Sept - 02 Sept, 2016 University of Greenwich

\section{Sant'Anna}

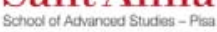

\section{Agenda}

- Topic and Background

○ Purpose

- Main Research Question (in the light of PC)

- Methodological and Theoretical Framework

○ Research Setting

○ Research Method

○ Preliminary Findings

- Conclusions

- Main potential implications 


\section{Topic \\ Performance- based budgeting}

- $\quad$ PBB has gained renewed attention over the last decades in light of New Public Management (Hood, 1991; Hyndman et al., 2014), although it is not a new concept.

Performance- based budgeting (PBB) could be defined as the process designed to strengthen the linkage between funding and results through the systematic use of formal performance information (Robinson, 2007)

- Despite its long history, still nowadays, PBB implies numerous challenges and problems, thus producing contrasting results.

"The history of performance budgeting is one of high hopes and disappointing achievements" (Dean, 1986, p. 1)

\section{Background PBB \& The New Public Management}

The key features of PBB lie in its managerial approach inspired by NPM

- Could private sector tools and methods be functional in and for the public sector?

\section{A controversial debate}

- "Ephemeral theme likely to fade" (Lynn, 1998, 232)

- Difficulties in meeting the expectations (Lapsley, 2008)

- Negative impacts:

- Diffusion of an entrepreneurial ethos (Morales et al., 2014)

- Public servant as a new homo oeconomicus (Hoskin, 2015)

- Privatization of moral concerns (Dobel, 1978)

- General decline of the public sphere (Lehman, 2010)

- Loss of a common understanding of the public interest (Johnston, 2015)
- Analysis of paradoxes to further develop administrative science (Hood and Peters, 2004)

- "NPM can work" (Dan and Pollitt, 2014)

- Influencing role of NPM nowadays (de Vries and Nemec, 2013)

- Call for reflection on NPM rationality assumptions (ter Bogt et al., 2015)

\section{Sant'Anna}




\section{Purpose \\ PBB \& Pragmatic constructivism}

The work wishes to adopt a pragmatic constructivist approach in order to understand and explain the functionality of private- inspired reforms in the public sector, with a focus on PBB.

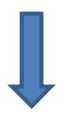

To find out whether the new model is able to construct reality or produces instead an illusion (Norreklit 2011), the work investigates, analyses, and compares legislative requirements and guidelines (model) with the documents adopted and published in implementation (practice) and the opinions expressed by actors (narrative).

\section{Sant'Anna}

\section{Main Research Question (in the light of PC)}

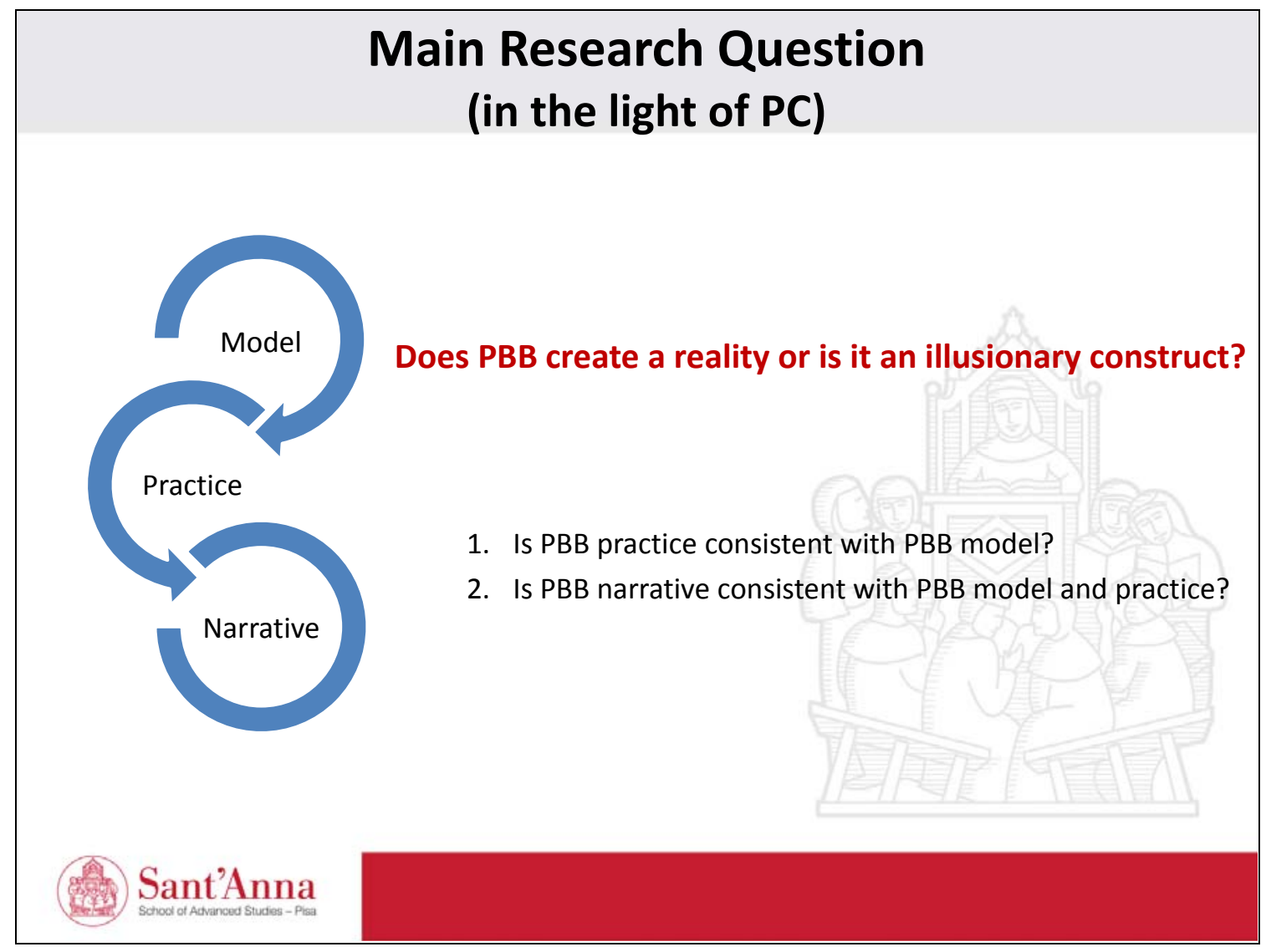




\section{Theoretical framework}

\section{"ILLUSION IS A NON-FUNCTIONAL RELATIONS BETWEEN THE ACTOR AND WORLD"}

(Norreklit, 2011)

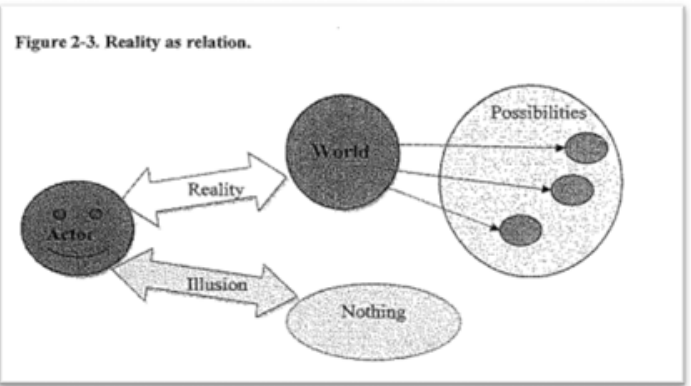

"Illusions are when the actor does things based on illusion, then activities do not succeed. Reality is what appears in a functioning actor-world relationship, illusion is what appears in a non-functional actor-world relationship." (Nørreklit, L., 2011)

$$
\begin{array}{ll}
\text { Reality: } & \text { Actor }- \text { (adequate representation) - World (Factual possibilities) } \\
\text { Illusion: } & \text { Actor }- \text { (inadequate representation) - Nothing (Delusion) }
\end{array}
$$

"Fictions, delusions, illusions, dreams, hope, etc. - all of them are constructs. They imagine worlds that do not exist. We need this ability to construct representations of a world. However, we also need to be able to distinguish which of these constructs are real and which not....." (Nørreklit, L., forthc.)

\section{Sant'Anna}

\section{Research setting}

\section{Performance-based budgeting in Italy}

Two reforms have paved the way to the introduction of PBB in Italy in 2009:

1. Law on accounting and public finance (196/2009) - reform of public budget

2. Legislative Decree 150/2009 - introduction of a performance management cycle

\section{REFORM OF PUBLIC BUDGET}

- New structure of the budget (Missions and programs)

- Strengthened focus on what should be done rather than on who uses money

- Reporting of performance information (Integrative notes to the Budget and to the Final Statement)
INTRODUCTION OF A PERFORMANCE MANAGEMENT CYCLE

- Production, monitoring and reporting of performance information (indicators, measures, targets, ...)

- New documents, ex-ante (Performance plan) and ex-post (Performance report)

- Ad-hoc independent performance units (OIV) and independent authority (ANAC)

\section{Sant'Anna}




\section{Research method}

Qualitative approach based on the collection and analysis of data in one central administration in Italy.

Analysis of three kinds of data:

- Legislative texts and ANAC report and guidelines

$\rightarrow$ MODEL

- Documents produced in PBB implementation (e.g. Performance plans, performance reports and integrative notes to budget)

-> PRACTICE

○ Semi-structured and face-to face interviews

$>$ NARRATIVE

\section{Sant'Anna}

\section{Setting of interviews}

\section{Focus on the implementation of PBB in one Ministry}

The interviews involved:

- OIV (Independent Performance Unit)

- Division 'Economic and financial management and planning' of the Responsibility Center

- Ministry for Finance

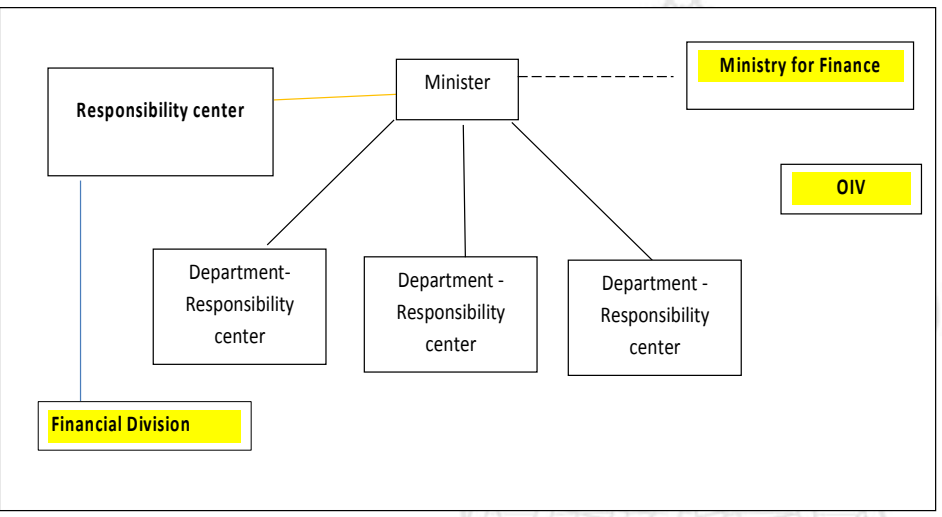




\section{Preliminary findings (1/2)}

Inconsistencies between PBB theory, practice and narrative:

a) Conceptual

b) Implementation

Due to a failure in terms of communication of the aims of the reform, definition of factual possibilities, promotion of private values that conflict with the ethics of public servants.

\section{Conceptual inconsistencies about:}

- WHAT?

Terminology confusion:

- What is performance in the public sector? Is it always measurable?

- What are the manageable "objectives"? (e.g. structural objective vs. strategic objective)

- WHY?

The PBB aims:

- Is it a control tool or a tool to provide awards/incentives to public managers?

- Is it a mean to provide information to citizens for improving accountability and allowing aware choices?

Sant'Anna

\section{Preliminary findings $(2 / 2)$}

Implementation inconsistencies due to:

HOW?

- Rationality of the reform program: «proliferation of documents» rather than re engineering of systems (procedures)

- Limited powers of control bodies (autonomy of OIV and ANAC).

- Lack of credibility of the system

- Structural limitations in public decision-making process: where is the flexibility?

- Limited resources: is it possible to re-allocate them?

- Limited coordination across responsibility centers.

- Inherent limits of standardization vs. specificities of public sector organizations.

- Uncertainty and variability of strategies and context.

\section{Sant'Anna}




\section{Conclusions}

The PBB reform may result in a failure. Indeed, it produces illusions rather than real changes as it is based on the following assumptions:

1. Faith in the effectiveness of the translation of private sector performance practices into the public sector

- Underestimation of the problem of measuring outcomes of "public policies"

2. Faith in the possibility to have a cultural and organizational change in PS by a top-down processes (PBB reform)

3. Myth of the clear separation between politics and administration in terms of decision-making processes and implementing procedures.

Sant'Anna

\section{Main potential implications}

1. The work contributes to the literature on performance budgeting by deepening the understanding of its functionality through a focus on the integration between three levels of analysis (model, practice and narrative).

2. The work contributes to the debate on NPM by providing empirical evidence on the conditions conditions which affects the functionality of privateinspired reforms in and for the public sector.

3. The work contributes to pragmatic constructivism by using its dichotomy between reality and illusion to develop an understanding of what are the conditions for successful practices in a specific context and as they result from the coherence between model, practice and narrative. 


\section{References}

Bogt, H. J., Helden, G. J., \& Kolk, B. (2015). Challenging the NPM Ideas About Performance Management: Selectivity and Differentiation in Outcome-Oriented Performance Budgeting. Financial Accountability \& Management, 31(3), 287-315.

Cinquini, L., Tenucci, A., Campanale, C., Passetti, E. (2013). Understanding performance measurement in public organization under pragmatic constructivism. The Actor Reality Perspective Conference.

Dobel, J. P. (1978). The corruption of a state. American Political Science Review, 72(03), 958-973.

Hood, C. (1991). A public management for all seasons?. Public administration, 69(1), 3-19.

Hood, C. (1995). The "New Public Management" in the 1980s: variations on a theme. Accounting, organizations and society, 20(2), 93-109.

Hoskin, K. (2015). What about the box?" Some thoughts on the possibility of 'corruption prevention', and of 'the disciplined and ethical subject. Critical Perspectives on Accounting, 28, 71-81.

Hyndman, N., Liguori, M., Meyer, R. E., Polzer, T., Rota, S., \& Seiwald, J. (2014). The translation and sedimentation of accounting reforms. A comparison of the UK, Austrian and Italian experiences. Critical Perspectives on Accounting, 25(4), 388-408.

Johnston, M. (2015). Making transparency real? Accounting and popular participation in corruption control. Critical Perspectives on Accounting, 28, 97-101.

Lapsley, I. (2008). The NPM agenda: back to the future. Financial accountability \& management, 24(1), 77-96.

Lehman, G. (2010). Perspectives on accounting, commonalities \& the public sphere. Critical Perspectives on Accounting, 21(8), 724-738.

Lynn Jr, L. E. (1998). The new public management: How to transform a theme into a legacy. Public Administration Review, 231-237.

Mitchell, F., Nielsen, L. B., Nørreklit, H., \& Nørreklit, L. (2013). Scoring strategic performance: a pragmatic constructivist approach to strategic performance measurement. Journal of Management \& Governance, 17(1), 5-34.

Morales, J., Gendron, Y., \& Guénin-Paracini, H. (2014). The construction of the risky individual and vigilant organization: A genealogy of the fraud triangle. Accounting, Organizations and Society, 39(3), 170-194.

Nørreklit, L. (2011), “Actors and reality: a conceptual framework for creative governance", in Jakobsen, M., Johansson, I.-L. and Nørreklit, H. (Eds.), An Actor's Approach to Management Conceptual Framework and Company Practices, Djøf/Jurist- og Økonomforbundet, pp. 7-38.

Nørreklit, L., Nørreklit, H., \& Israelsen, P. (2006). The validity of management control topoi: towards constructivist pragmatism. Management Accounting Research, 17(1), 42-71.

OECD (2007). Performance budgeting in OECD Countries. OECD Publishing.

Robinson, M. (2007). Performance Budgeting: Linking Funding and Results. International Monetary Fund.

Stiglitz, J. E. (1989). The economic role of the state.

Yin, R. (1994). Case study research: Design and methods. Beverly Hills. 